\title{
Procalcitonin levels versus Microbiological profile in Central line associated bloodstream infections (CLABSI) of patients on Hemodialysis
}

\author{
Madhura NS ${ }^{1}$, Shashikala N², Mythri Shankar ${ }^{3}$, Kowsalya $\mathbf{R}^{4}$, Mythri KM ${ }^{5}$ \\ ${ }^{1}$ Assistant Professor, ${ }^{4}$ Professor, Department of Biochemistry, Institute of Nephro-Urology, Bangalore, India, ${ }^{2}$ Assistant \\ Professor, ${ }^{5}$ Professor, Department of Microbiology, Institute of Nephro-Urology, Bangalore, India, ${ }^{3}$ Assistant Professor \\ of Nephrology, Institute of Nephro-Urology, Bangalore. India
}

Background: CLABSI is one of the most common forms of hospital acquired systemic infection(sepsis), associated with high mortality. Although Procalcitonin (PCT) is proved be the earliest and specific marker for the diagnosis of sepsis, there is relatively sparse literature on the usage of this marker in CLABSI with chronic kidney disease (CKD). Aims and Objective: To correlate the Procalcitonin levels with microbiological profile of CLABSI CKD patients. Materials and Methods: A retrospective case control study was conducted in a tertiary care Nephro-Urology hospital in Bangalore, from January 2019 to December 2019 including all CKD patients (age $>20$ years) with central venous catheter undergoing Hemodialysis. Based on blood culture reports of these patients, they were divided into CLABSI (positive growth), and no growth. Procalcitonin was analyzed in both the groups. Statistical analysis was done using SPSS software version 17. Results: Sixtyone percentage of the CKD patients of mean age 46 years had CLABSI. Most common isolate in CLABSI CKD was Staphylococcus aureus (35\%), followed by Escherichia coli $(19 \%)$, Klebsiella pneumoniae (10\%). Mean PCT was significantly higher ( $\mathrm{p}$ value 0.001$)$ in CP-CKD (Culture positive-chronic kidney disease) patients $(36.1 \pm 35 . \mathrm{ng} / \mathrm{ml}$ ) compared to $\mathrm{CN}-\mathrm{CKD}$ (Culture negative-chronic kidney disease) $(4.6 \pm 10.0 . \mathrm{ng} / \mathrm{ml}$ ). Also mean PCT for Gram positive (GP) isolates $(28.7 \pm 30.2$ ) was significantly lower (P value 0.0008 ) than that for gram negative $(\mathrm{GN})$ isolates $(53.6 \pm 33.7)$. Conclusion: The study highlights higher incidence of CLABSI in CKD patients. Higher PCT values were observed in gram negative bacteria compared to gram positive, indicating its probable role for differentiating CLABSI due to gram-positive and gram-negative bacteria.

Key words: Central line associated bloodstream infections; Procalcitonin; Chronic kidney disease; Blood culture

\section{INTRODUCTION}

Sepsis is the systemic inflammatory response developed by the body immune system to the invasion of various infectious pathogens. ${ }^{1}$ It affects almost all the organs of the body and hence presence of various markers of human host markers like cytokines, receptor biomarkers, cell markers etc. is evident of sepsis. ${ }^{2}$ Although total leukocyte count and $\mathrm{C}$ - reactive protein (CRP) are used as the conventional markers for the diagnosis of sepsis, absence of these markers will not exclude sepsis, also these markers lack sensitivity and specificity. ${ }^{3}$ Procalcitonin (PCT) is produced by the thyroid glands for calcium regulation. It gets broken down to calcitonin for the same purpose. Though all tissues in the body have the ability to produce PCT, only the C cells of thyroid gland produce required enzymes to cleave PCT to calcitonin in order to maintain calcium balance. During sepsis, there is a surge of cytokines such as IL-6, 
TNF- $\alpha$ and IL- $1 \beta$ which stimulate the production of PCT from non-thyroid tissues of the body. Hence, there is an increase in PCT levels during sepsis.

Thus, it serves as an early marker of sepsis as it is increased within four hours of sepsis and reaches its maximum within six hours indicating that PCT is a better biomarker of sepsis than other traditional ones ${ }^{4,5} \mathrm{Also}, \mathrm{PCT}$ is more indicative of bacterial infections as its values are normal in viral and fungal infections, and other noninfectious inflammatory conditions. ${ }^{6,7}$

A central line-associated bloodstream infection (CLABSI) is a bloodstream infection mainly confirmed by laboratory investigation, which develops after two calendar days of placement of central venous line, with no evidence of infection at any other site. ${ }^{8,9}$ CLABSI is one of the most common forms of hospital acquired systemic infection(sepsis), which requires a prolonged hospital stay, high risk of mortality and has high cost burden. ${ }^{10,11}$ More than $50 \%$ of the nosocomial bacteremia are known to have a source from intravascular access. ${ }^{12} \mathrm{~A}$ recent survey from United states has reported that around 2,50,000 intravascular blood stream infections are detected with a mortality rate of $12 \%-25 \%$ annually. ${ }^{13,14} \mathrm{~A}$ survey by International Nosocomial Infection Control Consortium (INICC) included intensive care units of 15 developing countries and reported that CLABSI occurs at a rate of 4.1 per 1000 central lines. ${ }^{15}$

Hence, earliest diagnosis of CLABSI is very important for the clinician so that an appropriate treatment can be initiated in order to prevent morbidity and mortality associated with that. Although PCT is proved be the earliest and specific marker for the diagnosis of sepsis, there is relatively sparse literature on the usage of this marker in the diagnosis and management of central line associated blood stream infections. In the present study we focus on detecting the incidence of CLABSI in chronic kidney disease (CKD) patients on hemodialysis (HD), and correlation of procalcitonin with microbiological profile of CLABSI. We also focus on studying antibiotic resistance pattern of CLABSI in CKD patients and its possible correlation with procalcitonin.

\section{MATERIALS AND METHODS}

This is a retrospective case control study conducted in a tertiary care Nephro-Urology hospital in Bangalore, Karnataka, South India, from January 2019 to December 2019. CKD patients (age $>20$ years) with central venous catheter undergoing hemodialysis were enrolled in the study. Blood culture reports of all such patients were collected. As part of hospital policy, blood samples are collected as per standard guidelines and sent for culture and S. PCT levels prior to initiating empirical antibiotic therapy. As per the culture reports, subjects were divided into 2 groups, group 1 with culture positive cases and group 2 with culture negative cases. Procalcitonin was analyzed in both the groups. Patients who had infection from any source other than central venous catheter were excluded from the study.

\section{Inclusion criteria}

All CKD patients (Age $>20$ years) presenting with signs and symptoms suspicious of CLABSI such as fever, chills, malaise, hypotension with no other localizing signs of infection having central venous catheter (temporary or permanent) in situ for more than two consecutive calendar days.

\section{Exclusion criteria}

1) CKD patients with other known causes of infection.

2) $\mathrm{CKD}$ patients with other comorbidities which cause high PCT values.

\section{Sample collection and laboratory analysis of the sample}

Blood culture and antimicrobial susceptibility test

Paired blood cultures (one each from the central line and peripheral vein) were collected with strict aseptic precautions, labelled appropriately and incubated in BacT/ALERT 3D Automated Blood Culture system (BioMérieux). When there was difficulty in collecting peripheral blood cultures as in CKD patients, two or more samples were collected from different lumens of a multi-lumen central line catheter ${ }^{17}$. When the instrument flagged positive, subcultures were made on to MacConkey agar and 5\% defibrinated sheep blood agar and incubated overnight at $37^{\circ} \mathrm{C}$ after noting the time. The plates were then observed for colony morphology and the isolate identified with standard biochemical tests. Following this, antimicrobial susceptibility was performed by Kirby-Bauer disc diffusion method as per current CLSI guidelines. ${ }^{18,19}$

\section{Biochemical parameters}

After taking all aseptic precautions, $5 \mathrm{ml}$ of venous blood sample was collected from median cubital vein, and was centrifuged for 15 mins. Serum sample thus separated was used for analysis. All the parameters were assayed in our Biochemistry laboratory using Abbott CI 4100, chemistry and immunoassay analyzer. Urea and creatinine were assayed using enzymatic method, urea by Urease method and creatinine by Jaffe's method.

Procalcitonin was measured using chemiluminescent microparticle immunoassay (CMIA), with a measuring range of $0.02-100 \mathrm{ng} / \mathrm{ml}$. C-reactive protein (CRP) was measured using Immunoturbidimetric method, with the reportable range of 0.50 to $30.00 \mathrm{mg} / \mathrm{dl}$. 


\section{Statistical analysis}

Statistical analysis was performed using Statistical Package for the Social Sciences software Version 17. Chi square test was used to find the significance among incidence and prevalence rates. Unpaired independent student t test was used to find out significance among independent variables.

\section{RESULTS}

One-hundred ten consecutive patients as mentioned in the inclusion criteria. Sixty-eight (61.8\%) cases had a positive blood culture. $42(38.2 \%)$ cases had no growth on blood culture. $51 \%$ of the culture positives were in the age group of 35 to 50 years. There was no statistically significant difference between male and females with respect to culture positivity (Table 1).

Table 2 shows the comparison of clinical data in culture positive $(\mathrm{CP}) \mathrm{CKD}$ and culture negative $(\mathrm{CN}) \mathrm{CKD}$ patients. Mean age of the patients in CP-CKD and CN-CKD group was 46 years and 48 years respectively (Table 2 ).

Mean duration of hemodialysis was 426 days and 397 days in culture positive CKD and culture negative CKD respectively. There was no significant association between

\begin{tabular}{|c|c|c|c|}
\hline Total (n) & $\begin{array}{c}\text { Culture } \\
\text { positive } \\
\mathrm{n}(\mathrm{n} \%)\end{array}$ & $\begin{array}{c}\text { Culture } \\
\text { negative } \\
\text { n (n\%) }\end{array}$ & $\begin{array}{c}\text { P value } \\
\text { (Chi Square } \\
\text { value) }\end{array}$ \\
\hline $\begin{array}{l}\text { Number of HD patients } \\
\text { on central line }\end{array}$ & $68(61.8 \%)$ & $42(38.2 \%)$ & \\
\hline \multicolumn{4}{|l|}{ Age group (years) } \\
\hline $20-35$ & $21(30 \%)$ & 18 & 0.31 \\
\hline $35-50$ & $35(51 \%)$ & 20 & ( $\chi^{2}$ value: \\
\hline$>50$ & $12(17 \%)$ & 4 & $2.305)$ \\
\hline Sex & & & 0.808 \\
\hline Male(54) & $34(62 \%)$ & $20(38 \%)$ & $\left(\chi^{2}\right.$ value: \\
\hline Female(56) & $34(60 \%)$ & $22(39 \%)$ & $0.05)$ \\
\hline
\end{tabular}

\begin{tabular}{|c|c|c|c|}
\hline Parameters & $\begin{array}{c}\text { Culture } \\
\text { positive } \\
\text { (mean士sd) }\end{array}$ & $\begin{array}{c}\text { Culture } \\
\text { negative } \\
\text { (mean士sd) }\end{array}$ & $P$ value \\
\hline Age(Years) & $46 \pm 16$ & $48 \pm 14$ & 0.5 \\
\hline $\begin{array}{l}\text { Duration of } \\
\text { hemodialysis(Days) }\end{array}$ & $426 \pm 237$ & $397 \pm 212$ & 0.5 \\
\hline $\begin{array}{l}\text { Duration of } \\
\text { catheterisation(Days) }\end{array}$ & $50 \pm 30$ & $15 \pm 5$ & 0.0001 \\
\hline PCT (ng/ml) & $36.1 \pm 35.7$ & $4.6 \pm 1.3$ & 0.0001 \\
\hline $\mathrm{CRP}(\mathrm{mg} / \mathrm{dl})$ & $24 \pm 11$ & $12 \pm 6$ & 0.0001 \\
\hline $\begin{array}{l}\text { Leucocyte count(cells/ } \\
\text { cubic mm) }\end{array}$ & $17313 \pm 7796$ & $8775 \pm 4806$ & 0.0001 \\
\hline Creatinine(mg/dl) & $12.3 \pm 5.6$ & $8.4 \pm 3.6$ & \\
\hline
\end{tabular}

the culture positive growths and duration of hemodialysis (Table 2).

Duration of catherization was significantly higher in culture positive CKD patients (mean $50 \pm 30$ days) compared to culture negative CKD (mean $15 \pm 5$ days) with $\mathrm{P}$ value of 0.0001 at $95 \%$ confidence interval (CI) 44.2-25.7 (Table 2).

Mean PCT was significantly higher in CP-CKD patients (36. $1 \pm 35 . \mathrm{ng} / \mathrm{ml})$ compared to CN CKD $(4.6 \pm 10.0 \mathrm{ng} / \mathrm{ml})$ with a p value of 0.0001 at $95 \%$ CI (20.3-42.6) (Table 2).

Both CP-CKD and CN-CKD patients were divided into 4 subgroups based on the PCT values which were a) PCT $<0.5 \mathrm{ng} / \mathrm{ml}$, b) $0.5-2.0 \mathrm{ng} / \mathrm{ml}$, c) $2.0-10 \mathrm{ng} / \mathrm{ml}$ and d) $>10 \mathrm{ng} / \mathrm{ml} .37(54 \%)$ of the culture positive CKD patients, fell into PCT $>10$ group(Group d), which was statistically significant compared to culture negative CKD patients (Table 3) (Figure1).

Other markers of inflammation, C-reactive protein (CRP), total leucocyte count (TLC) were also compared, which revealed significantly higher value of CRP ( $p$ value: 0.0001 ) in CP-CKD $(24 \pm 11 \mathrm{mg} / \mathrm{dl})$ compared to CN-CKD $(12 \pm 6 \mathrm{mg} / \mathrm{dl})$ and TLC was also significantly high in CPCKD (P value: 0.0001) (Table 2).

On comparing PCT values between gram positive $(28.7 \pm 30.2)$ and gram negative isolates (53.6 \pm 33.7$)$ of culture positive patients, there was significantly ( $\mathrm{P}$ value-0.0008) increased PCT values in gram negative CLABSI compared to gram positive CLABSI (Table 4).

Among a total of 68 culture positive patients, 28 (41\%) were gram positive bacteria, 28 (41\%) were gram negative bacteria and $5(7 \%)$ were fungal pathogens. Most common

\begin{tabular}{|c|c|c|c|}
\hline Inflammatory markers & $\begin{array}{c}\text { Culture } \\
\text { positive } \\
n(n \%)\end{array}$ & $\begin{array}{c}\text { Culture } \\
\text { negative } \\
n(n \%)\end{array}$ & $\begin{array}{c}\text { P value } \\
\text { (Chi Square } \\
\text { value) }\end{array}$ \\
\hline \multicolumn{4}{|l|}{ PCT (ng/ml) } \\
\hline$<0.5$ & $13(19 \%)$ & $16(38 \%)$ & \\
\hline $0.5-2$ & $8(11 \%)$ & $7(16 \%)$ & 0.00065 \\
\hline 2- 10 & $10(14 \%)$ & $16(38 \%)$ & ( $\chi^{2}$ value: 22.1$)$ \\
\hline$>10$ & $37(54 \%)$ & $5(11 \%)$ & \\
\hline $\mathrm{CRP}(\mathrm{mg} / \mathrm{dl})$ & & & 0.00001 \\
\hline$>32$ & $31(45 \%)$ & $1(1.4 \%)$ & ( $\chi^{2}$ value: 23.4$)$ \\
\hline$<32$ & $37(55 \%)$ & $41(98.6 \%)$ & \\
\hline $\begin{array}{l}\text { Leucocytosis } \\
\left(\text { TLC }>11000 \text { cells } / \mathrm{m}^{3}\right)\end{array}$ & $55(80 \%)$ & $12(17 \%)$ & $\begin{array}{c}0.0001 \\
\left(\chi^{2} \text { value: } 29.8\right)\end{array}$ \\
\hline Fever & $10(14 \%)$ & $5(11 \%)$ & $\begin{array}{c}0.67 \\
\left(\chi^{2} \text { value: } 29.8\right)\end{array}$ \\
\hline
\end{tabular}




\begin{tabular}{|c|c|c|c|}
\hline $\begin{array}{l}\text { PCT in GPB CLABSI, Mean } \pm \text { SD } \\
\text { Median }\end{array}$ & $\begin{array}{c}\text { PCT in GNB CLABSI, Mean } \pm S D \\
\text { Median }\end{array}$ & $P$ value (std error) & Significance level \\
\hline $\begin{array}{l}28.7 \pm 30.2 \\
36.2(0.11-100)\end{array}$ & $\begin{array}{c}53.6 \pm 33.7 \\
77.3(1.2-100)\end{array}$ & $\begin{array}{l}0.0008 \\
(8.428)\end{array}$ & Significant \\
\hline
\end{tabular}

\begin{tabular}{|c|c|c|}
\hline Pathogen isolated & Number (\%) & $\begin{array}{l}\text { PCT Median } \\
\text { (Range) }\end{array}$ \\
\hline \multicolumn{3}{|l|}{ Gram positive bacteria } \\
\hline 1. Staphylococcus aureus & $24(35 \%)$ & $52.6(0.11-100)$ \\
\hline 2. Coagulase negative & $2(2.9 \%)$ & $17.5(17-18)$ \\
\hline staphylococci(CONS) & $2(2.9 \%)$ & $3.7(3.3-4.2)$ \\
\hline \multicolumn{3}{|l|}{ 3. Enterococcus fecalis } \\
\hline \multicolumn{3}{|l|}{ Gram negative bacteria } \\
\hline 1. Klebsiella pneumoniae & $7(10 \%)$ & $77.2(39.2-100)$ \\
\hline 2. Pseudomonas aeruginosa & $3(2.9)$ & $53.5(19.8-72.0)$ \\
\hline 3. Escherichia coli & $13(19 \%)$ & $63.2(0.18-79.7)$ \\
\hline 4. Acinetobacter species & $2(2.9 \%)$ & $5.5(1.2-9.4)$ \\
\hline 5. Enterobacter species & $3(4.4 \%)$ & $56(3-100)$ \\
\hline \multicolumn{3}{|l|}{ Fungal growth } \\
\hline 1. Candida albicans & $4(5.8 \%)$ & $2.85(0.2-3.1)$ \\
\hline 2. Non Candida albicans & $1(1.4 \%)$ & 2.71 \\
\hline Contaminants (Micrococi) & $6(8.8)$ & $23.4(0.32-99.2)$ \\
\hline Total & $68(100 \%)$ & \\
\hline
\end{tabular}

Table 6: Antibiotic resistance pattern for Gram positive isolates

\begin{tabular}{lcccccc}
\hline Antibiotics & N & S & I & R & Resistance \% & Efficacy \\
\hline Vancomycin & 28 & 28 & 0 & 0 & $0 \%$ & $100 \%$ \\
Tiecoplanin & 28 & 28 & 0 & 0 & $0 \%$ & $100 \%$ \\
Linezolid & 28 & 28 & 0 & 0 & $0 \%$ & $100 \%$ \\
Cotrimoxazole & 28 & 4 & 2 & 23 & $82.1 \%$ & $17.9 \%$ \\
Doxycyclin & 28 & 5 & 1 & 23 & $82.1 \%$ & $17.9 \%$ \\
Clindamycin & 28 & 25 & 2 & 1 & $3.5 \%$ & $96.5 \%$ \\
Levofloxacin & 28 & 2 & 2 & 24 & $85.7 \%$ & $14.3 \%$
\end{tabular}

$\mathrm{N}$ - number of susceptibility tests, S-sensitive, I-intermediate, R-resistant,

Resistance $(\%)=\mathrm{R} / \mathrm{N} \times 100 \%$, EFFICACY $(\%)=\mathrm{S}+\mathrm{I} / \mathrm{N} \times 100 \%$.

species that were isolated were Staphylococcus aureus 24(35\%), followed by Escherichia coli 13 (19\%), Klebsiella pneumoniae 7 $(10 \%)$ (Table 5) (Figure 2).

Antibiotic susceptibility tests were done for both grampositive isolates and gram-negative isolates. Antibiotic resistance and efficacy pattern for GP and GN isolates are demonstrated in the Table 6 and 7.

In Gram positive isolates, levofloxacin, cotrimoxazole and doxycycline showed resistance rates of more than $50 \%$, and vancomycin, linezolid, teicoplanin showed zero resistance indicating 100\% efficacy (Table 6)(Figure 3).

In Gram negative isolates, aztreonam, cefotaxime, ciprofloxacin, ceftazidime, levofloxacin, amikacin,

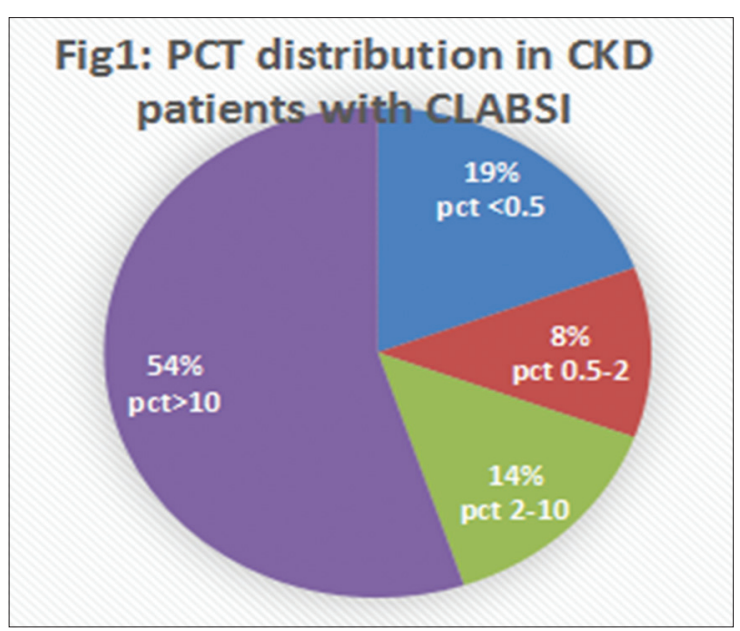

Figure 1: PCT distribution in CKD patients with CLABSI

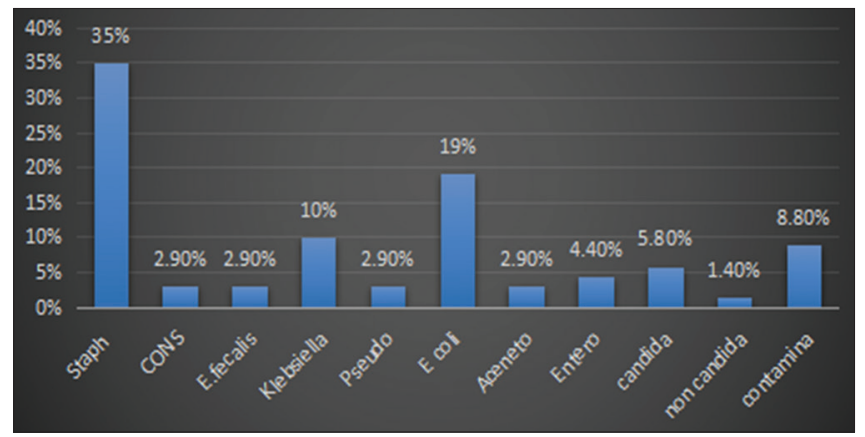

Figure 2: Microbiological profile of CLABSI in CKD patients

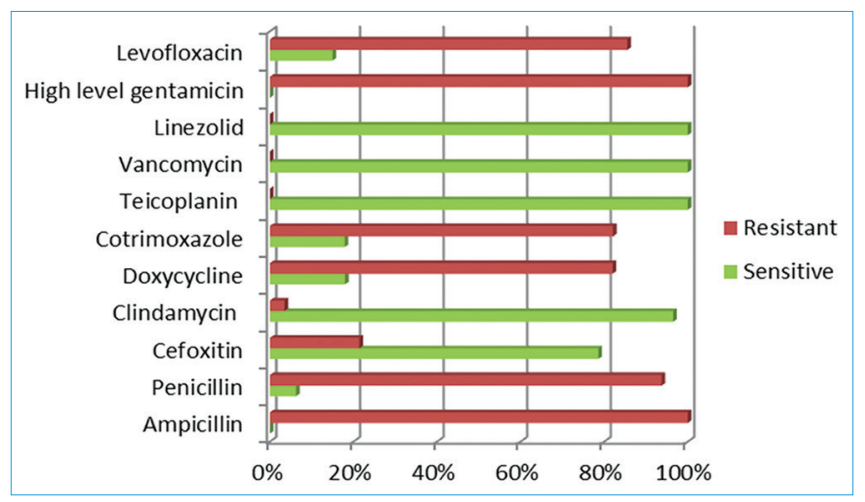

Figure 3: Antibiogram of gram-positive organisms

gentamycin, showed more than $50 \%$ resistance, whereas polymyxin B, imipenem, meropenem, cefoperazonesulbactam showed zero resistance indicating $100 \%$ efficacy (Table 7) (Figure 4). 


\begin{tabular}{|c|c|c|c|c|c|c|}
\hline Antibiotics & $\mathbf{N}$ & $S$ & I & $\mathbf{R}$ & Resistance \% & Efficacy \\
\hline Aztreonam & 28 & 4 & 1 & 23 & $81 \%$ & 19 \\
\hline Cefotaxime & 28 & 2 & 1 & 25 & $89.2 \%$ & 10.8 \\
\hline Ciprofloxacin & 28 & 4 & 1 & 23 & $82.1 \%$ & 17.9 \\
\hline Colistin & 28 & 28 & 0 & 0 & $0 \%$ & 100 \\
\hline Ceftazidime & 28 & 5 & 0 & 23 & $82 . \% 1$ & 17.9 \\
\hline Ertapenem & 28 & 1 & 1 & 26 & $92.8 \%$ & 7.2 \\
\hline Imipenem & 28 & 27 & 0 & 1 & $3.5 \%$ & $96.5 \%$ \\
\hline Meropenem & 28 & 28 & 0 & 0 & $0 \%$ & 100 \\
\hline $\begin{array}{l}\text { Cefoperazone- } \\
\text { Sulbactam }\end{array}$ & 28 & 28 & 0 & 0 & $0 \%$ & 100 \\
\hline $\begin{array}{l}\text { Piperacillin- } \\
\text { Tazobactam }\end{array}$ & 28 & 6 & 2 & 20 & $71.4 \%$ & 29.6 \\
\hline Polymyxin-B & 28 & 28 & 0 & 0 & $0 \%$ & 100 \\
\hline Levofloxacin & 28 & 3 & 2 & 23 & $82.1 \%$ & 17.9 \\
\hline Tigecycline & 28 & 28 & 0 & 0 & $0 \%$ & 100 \\
\hline Amikacin & 28 & 14 & 0 & 14 & $50 \%$ & 50 \\
\hline
\end{tabular}

$\mathrm{N}$ - number of susceptibility tests, S-sensitive, I-intermediate, R-resistant, Resistance $(\%)=\mathrm{R} / \mathrm{N} \times 100 \%$, EFFICACY $(\%)=\mathrm{S}+\mathrm{I} / \mathrm{N} \times 100 \%$.

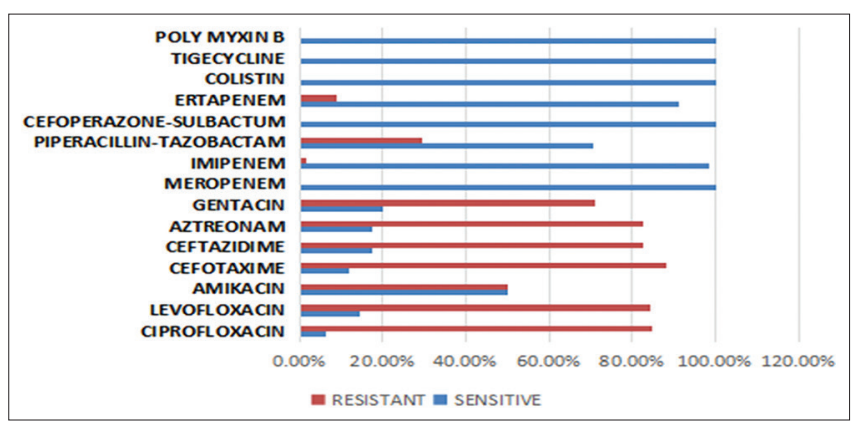

Figure. 4: Antibiogram of Gram-negative organisms

\section{DISCUSSION}

Central line associated blood stream infection (CLABSI) is defined by CDC, as recovery of a pathogen from a blood culture of a patient who had central line in place for more than two calendar days, where the infection cannot be related to any source, other than central line. ${ }^{16}$

CLABSI is one of the most common forms of hospital acquired infection in patients receiving hemodialysis (HD), with an estimated incidence of $12-25 \%{ }^{20-22}$

In the present study, culture positive CLABSI occurred in $61 \%$ (68 out of 110 ) of the CKD patients with central line on HD. All these patients were admitted in ICU. Most common organisms isolated from blood culture of CLABSI patients in our study was Staphylococcus aureus (54\%), followed by Escherichia coli, and Klebsiella species. Similar findings were observed in Lata et al study where incidence of CLABSI was around 30\% in ESRD patients with predominance of Staphylococcal isolates. ${ }^{23}$
Procalcitonin is known to be increased in patients with bacteremia as proved in many studies. ${ }^{24-26}$ In the present study PCT levels were significantly higher in Gram negative isolates compared to gram positive isolates. Similar results were seen in Charles et al who demonstrated the ability of PCT to differentiate between the systemic infection by gram positive and gram negative organisms in critically ill patients. ${ }^{27}$ Another study by St. Yan et al have recently proved that PCT can be used as a marker to distinguish between GNB and GPB infection, as well as between different bacterial species and infection sites. ${ }^{28}$

The present study is apparently one of very few studies done to correlate the PCT and microbiological profile of CLABSI in CKD patients. In the present study, PCT median values for different microbial growths of CLABSI are compared in order to evaluate the possibility that different PCT values could correspond to different microbial groups. Accordingly, PCT was found to be high in gram negative organisms than in gram positive. Also, Klebsiella pneumoniae species was associated with highest median PCT in CLABSI CKD patients in our study.

The process of producing PCT by the host in response to gram negative and gram positive bacterial infection is unclear. This might be attributed to the membrane composition of gram positive and gram negative bacteria. In Gram negative bacteria, the major cell membrane component is lipopolysaccharide (LPS) which is also a major component of endotoxin. Whereas, in gram positive bacteria the major cell membrane component is peptidoglycan (PGN). Both these components which are pathogen associated molecular patterns (PAMPs) are identified by pattern recognition receptors (PRRs) during the innate immune response. These PRRs constitute several families like toll like receptors (TLR) and C-type lectin receptors (CLRS). TLRs play a major role in detecting the bacteria. Proinflammatory cytokines are released when the PAMPs bind to TLRs initiating signaling pathways. TLR-4 identifies LPS as a ligand whereas PGN by TLR2. MyD88 dependent signaling pathway which releases cytokines like TNF- $\alpha$, IL-6 is activated when LPS binds to TLR4. Comparatively poor cytokine levels (TNF $\alpha$ and IL-6) are observed in gram positive infections due to TLR-3 dependent stimulation. These factors might lead to higher PCT levels in gram negative bacterial infections compared to gram positive ones. ${ }^{29}$

Different ranges of PCT indicates the different degree of systemic inflammation namely no risk of systemic inflammation $(\mathrm{PCT}<0.5 \mathrm{ng} / \mathrm{ml})$, moderate risk of systemic infection(PCT $0.5-2 \mathrm{ng} / \mathrm{m}$ ), high risk of systemic infection (PCT 2-10ng/ml), severe systemic infection or bacterial sepsis (PCT values $>10 \mathrm{ng} / \mathrm{ml}$ ) Harbart et al. ${ }^{29}$ The result 
of the present study revealed that $54 \%$ of the CLABSICKD patients had PCT $>10 \mathrm{ng} / \mathrm{ml}$, corresponding to severe systemic infection with mean PCT of $36.1 \mathrm{ng} / \mathrm{ml}$. This gives an indication that PCT cut off value for CLABSI $\mathrm{CKD}$ needs to be increased for better management of these patients.

The study also observed that $38 \%$ of CKD patients without CLABSI had PCT in the range $2-10 \mathrm{ng} / \mathrm{ml}$, corresponding to high risk systemic infection with mean PCT of $4.6 \mathrm{ng} / \mathrm{ml}$. This is in accordance with a few studies which have proved that PCT level can be higher than normal baseline values in CKD patients regardless of whether they have superimposed infection or not. ${ }^{30,31}$

The pathophysiology of elevated PCT in these patients is due to an increase in pro-inflammatory mediators that stimulate the immune system in CKD patients to cause the release of PCT into the circulation. ${ }^{32}$

Also, $19 \%$ of the CLABSI CKD patients in our study had a PCT of $<0.5$, indicating that low or normal PCT does not always exclude the presence of bacterial infection. This might be a cause in early course of bacterial infection, or infection due to a few bacterial species which may not be associated with high PCT.

Development of antibiotic resistance in CKD patients is a major problem which is encountered by the clinicians. In the present study, antibiotic susceptibility tests were done for antibiotics for both gram-positive isolates and gramnegative isolates.

In Gram positive isolates, levofloxacin, cotrimoxazole and doxycycline showed resistance rates of more than $50 \%$, and vancomycin, linezolid, teicoplanin showed zero resistance indicating 100\% efficacy. Six isolates $(25 \%)$ of Staphylococcus aureus were methicillin resistant (MRSA).

In Gram negative isolates, aztreonam, cefotaxime, ciprofloxacin, ceftazidime, levofloxacin, amikacin, gentamicin, showed more than $50 \%$ resistance, whereas polymyxin $\mathrm{B}$, imipenem, meropenem, cefoperazonesulbactam showed zero resistance indicating 100\% efficacy.

High sensitivity of these antibiotics contributes to their use as an option in empirical antibiotic therapy. Accordingly, our study suggests that vancomycin, linezolid and teicoplanin could be considered for empirical antibiotic therapy for gram positive infections, and imipenem, meropenem, cefoperazone-sulbactam could be used for gram negative infections of CLABSI-CKD patients. Large number of studies are needed in this aspect to arrive at this conclusion.
Early and appropriate administration of antibiotic therapy for serious infections is known to be associated with lower mortality, shorter duration of hospitalization, and reduced cost of health care. ${ }^{33}$ Hence, strategies need to be made for the judicial use of antibiotics in order to control the resistance and to improve their rational use. One such strategy is to use PCT guided antibiotic therapy. ${ }^{34-36}$ One of the largest studies conducted in this aspect was the use of procalcitonin to de-escalate antibiotic therapy, in acutely ill patients (PRORATA) trial, ${ }^{37} \mathrm{a}$ randomized controlled trial involving seven ICUs, where the criterion for stopping antibiotics was a decrease of PCT $\geq 80 \%$ from its peak value . concluding that PCT guided strategy was effective in reducing antibiotic exposure without any apparent adverse outcomes.

In the present study, though there was positive association between the development of antibiotic resistance and peaked PCT values, the result was not statistically significant. This may be due to smaller study population and shorter duration of the study indicating the requirement of further studies in this aspect. Also the association between PCT and leukopenia was not studied.

\section{CONCLUSION}

The study highlights higher incidence of CLABSI in CKD patients. Higher PCT values were observed in gram negative bacteria compared to gram positive, indicating its probable role for differentiating CLABSI due to grampositive and gram-negative bacteria. Most common isolate was Staphylococcus aureus, sensitive to most of the higher antibiotics like vancomycin, teicoplanin and linezolid, suggesting their use as empirical therapy in CLABSI -CKD patients.

\section{REFERENCES}

1. Bosmann M and Ward PA. The inflammatory response in sepsis. Trends Immunol. 2013;34(3):129-136.

https://doi.org/10.1016/j.it.2012.09.004

2. Sakr Y, Burgett U, Nacul FE, Reinhart K and Brunkhorst F. Lipopolysaccharide binding protein in a surgical intensive care unit: a marker of sepsis? Critical care medicine. 2008;36(7):2014-2022. https://doi.org/10.1097/CCM.0b013e31817b86e3

3. Alkholi UM, Abd Al-Monem N, Abd El-Azim AA and Sultan $\mathrm{MH}$. Serum procalcitonin in viral and bacterial meningitis. J Glob Infect Dis. 2011;3(1):14-18. https://doi.org/10.4103/0974-777X.77290

4. Dandona P, Nix D, Wilson MF, Aljada A, Love J, Assicot M, et al. Procalcitonin increase after endotoxin injection in normal subjects. J Clin Endocrinol Metab. 1994;79(6):1605-1608. https://doi.org/10.1210/jcem.79.6.7989463

5. Standage SW and Wong HR. Biomarkers for pediatric sepsis and septic shock. Expert Rev Anti Infect Ther. 2011;9(1):71-79. 
https://doi.org/10.1586/eri.10.154

6. Eberhard O, Langefeld I, Kuse E, Brunkhorst F, Kliem V, Schlitt H, et al. Procalcitonin in the early phase after renal transplantationwill it add to diagnostic accuracy? Clinical transplantation. 1998;12(3):206-211.

7. Eberhard OK, Haubitz M, Brunkhorst FM, Kliem V, Koch KM and Brunkhorst R. Usefulness of procalcitonin for differentiation between activity of systemic autoimmune disease (systemic lupus erythematosus/systemic antineutrophil cytoplasmic antibody-associated vasculitis) and invasive bacterial infection. Arthritis Rheum. 1997;40(7):1250-1256.

https://doi.org/10.1002/1529-0131(199707)40:7<1250::AIDART9>3.0.CO;2-A

8. Aloush SM and Alsaraireh FA. Nurses' compliance with central line associated blood stream infection prevention guidelines. Saudi Medical Journal. 2018;39(3):273.

https://doi.org/10.15537/smj.2018.3.21497

9. Hallam C, Jackson T, Rajgopal A and Russell B. Establishing catheter-related bloodstream infection surveillance to drive improvement. Journal of infection prevention. 2018;19(4):160-166. https://doi.org/10.1177/1757177418767759

10. Adrie C, Garrouste-Orgeas M, Ibn Essaied W, Schwebel C, Darmon M, Mourvillier B, et al. Attributable mortality of ICUacquired bloodstream infections: Impact of the source, causative micro-organism, resistance profile and antimicrobial therapy. $\mathrm{J}$ Infect. 2017;74(2):131-141.

https://doi.org/10.1016/j.jinf.2016.11.001

11. Glied S, Cohen B, Liu J, Neidell M and Larson E. Trends in mortality, length of stay, and hospital charges associated with health care-associated infections, 2006-2012. Am J Infect Control. 2016;44(9):983-989.

https://doi.org/10.1016/j.ajic.2016.03.010

12. Crnich CJ and Maki DG. The Role of Intravascular Devices in Sepsis. Curr Infect Dis Rep. 2001;3(6):496-506. https://doi.org/10.1007/s11908-001-0086-4

13. Dimick JB, Pelz RK, Consunji R, Swoboda SM, Hendrix CW and Lipsett PA. Increased resource use associated with catheterrelated bloodstream infection in the surgical intensive care unit. Arch Surg. 2001;136(2):229-234.

https://doi.org/10.1001/archsurg.136.2.229

14. Rello J, Ochagavia A, Sabanes E, Roque M, Mariscal D, Reynaga E, et al. Evaluation of outcome of intravenous catheterrelated infections in critically ill patients. Am J Respir Crit Care Med. 2000;162(3 Pt 1):1027-1030.

https://doi.org/10.1164/ajrccm.162.3.9911093

15. Rosenthal VD, Maki DG, Rodrigues C, Alvarez-Moreno C, Leblebicioglu $H$, Sobreyra-Oropeza $M$, et al. Impact of International Nosocomial Infection Control Consortium (INICC) strategy on central line-associated bloodstream infection rates in the intensive care units of 15 developing countries. Infect Control Hosp Epidemiol. 2010;31(12):1264-1272.

https://doi.org/10.1086/657140

16. Wright MO, Decker SG, Allen-Bridson K, Hebden JN and Leaptrot D. Healthcare-associated infections studies project: An American Journal of Infection Control and National Healthcare Safety Network data quality collaboration: Location mapping. Am J Infect Control. 2018;46(5):577-578.

https://doi.org/10.1016/j.ajic.2017.12.012

17. Collee JG, Miles R and Watt B. Tests for identification of bacteria. Mackie and McCartney practical medical microbiology. 1996; 14:131-149.

18. Isenberg HD. Essential procedures for clinical microbiology. ASM press Washington, DC; 1998.
19. Wayne P. Clinical and Laboratory Standards Institute: Performance standards for antimicrobial susceptibility testing: 20th informational supplement. CLSI document M100-S20 2010.

20. D'Agata EM, Mount DB, Thayer V and Schaffner W. Hospitalacquired infections among chronic hemodialysis patients. American Journal of Kidney Diseases. 2000;35(6):1083-1088. https://doi.org/10.1016/S0272-6386(00)70044-8

21. Marr KA, Kong L, Fowler VG, Gopal A, Sexton DJ, Conlon PJ, et al. Incidence and outcome of $<$ em $>$ Staphylococcus aureus $<$ I em> bacteremia in hemodialysis patients. Kidney International. 1998;54(5):1684-1689.

https://doi.org/10.1046/j.1523-1755.1998.00134.x

22. Taylor G, Gravel D, Johnston L, Embil J, Holton D, Paton S, et al. Incidence of bloodstream infection in multicenter inception cohorts of hemodialysis patients. American journal of infection control. 2004;32(3):155-160. https://doi.org/10.1016/j.ajic.2003.05.007

23. Lata C, Girard L, Parkins M and James MT. Catheter-related bloodstream infection in end-stage kidney disease: a Canadian narrative review. Can J Kidney Health Dis. 2016; 3:24. https://doi.org/10.1186/s40697-016-0115-8

24. Chirouze C, Schuhmacher H, Rabaud C, Gil H, Khayat N, Estavoyer J-M, et al. Low Serum Procalcitonin Level Accurately Predicts the Absence of Bacteremia in Adult Patients with Acute Fever. Clinical Infectious Diseases. 2002;35(2):156-161. https://doi.org/10.1086/341023

25. Luzzani A, Polati E, Dorizzi R, Rungatscher A, Pavan R and Merlini A. Comparison of procalcitonin and C-reactive protein as markers of sepsis. Crit Care Med. 2003;31(6):1737-1741. https://doi.org/10.1097/01.CCM.0000063440.19188.ED

26. Ugarte H, Silva E, Mercan D, De Mendonça A and Vincent JL. Procalcitonin used as a marker of infection in the intensive care unit. Crit Care Med. 1999;27(3):498-504. https://doi.org/10.1097/00003246-199903000-00024

27. Charles PE, Ladoire S, Aho S, Quenot J-P, Doise J-M, Prin S, et al. Serum procalcitonin elevation in critically ill patients at the onset of bacteremia caused by either Gram negative or Gram positive bacteria. BMC infectious diseases. 2008;8(1):38. https://doi.org/10.1186/1471-2334-8-38

28. Yan ST, Sun LC, Jia HB, Gao W, Yang JP and Zhang GQ. Procalcitonin levels in bloodstream infections caused by different sources and species of bacteria. The American journal of emergency medicine. 2017;35(4):579-583.

https://doi.org/10.1016/j.ajem.2016.12.017

29. Harbarth S, Holeckova K, Froidevaux C, Pittet D, Ricou B, Grau GE, et al. Diagnostic value of procalcitonin, interleukin-6, and interleukin-8 in critically ill patients admitted with suspected sepsis. American journal of respiratory and critical care medicine. 2001;164(3):396-402.

https://doi.org/10.1164/ajrccm.164.3.2009052

30. Level C, Chauveau P, Delmas Y, Lasseur C, Pellé G, Peuchant $E$, et al. Procalcitonin: a new marker of inflammation in haemodialysis patients? Nephrology Dialysis Transplantation. 2001;16(5):980-986.

https://doi.org/10.1093/ndt/16.5.980

31. Meisner M, Schmidt J, Hüttner $H$ and Tschaikowsky K. The natural elimination rate of procalcitonin in patients with normal and impaired renal function. Intensive care medicine. 2000;26(2):S212-S216. https://doi.org/10.1007/BF02900740

32. Dahaba AA, Rehak $\mathrm{PH}$ and List WF. Procalcitonin and C-reactive protein plasma concentrations in nonseptic uremic 
patients undergoing hemodialysis. Intensive care medicine. 2003;29(4):579-583.

https://doi.org/10.1007/s00134-003-1664-8

33. Berkowitz DM and Martin GS. Sepsis and sex: can we look beyond our hormones? Chest. 2007;132(6):1725-1727. https://doi.org/10.1378/chest.07-2001

34. Hochreiter M, Köhler T, Schweiger AM, Keck FS, Bein B, von Spiegel T, et al. Procalcitonin to guide duration of antibiotic therapy in intensive care patients: a randomized prospective controlled trial. Critical Care. 2009;13(3):1-7. https://doi.org/10.1186/cc7903

35. Hohn A, Schroeder S, Gehrt A, Bernhardt K, Bein B, Wegscheider K, et al. Procalcitonin-guided algorithm to reduce length of antibiotic therapy in patients with severe sepsis and septic shock. BMC infectious diseases. 2013;13(1):1-9.

https://doi.org/10.1186/1471-2334-13-158

36. Schuetz P, Beishuizen A, Broyles M, Ferrer R, Gavazzi G, Gluck EH, et al. Procalcitonin (PCT)-guided antibiotic stewardship: an international experts consensus on optimized clinical use. Clinical Chemistry and Laboratory Medicine. (CCLM) 2019;57(9):1308-1318.

https://doi.org/10.1515/cclm-2018-1181

37. Bouadma L, Luyt C-E, Tubach F, Cracco C, Alvarez A, Schwebel $C$, et al. Use of procalcitonin to reduce patients' exposure to antibiotics in intensive care units (PRORATA trial): a multicentre randomised controlled trial. The Lancet. 2010;375(9713):463-474.

https://doi.org/10.1016/S0140-6736(09)61879-1

\section{Author's Contribution:}

MNS, SN, MS - Conceived the idea of the study, Developed the theory and performed the computations, Data analysis and manuscript preparation, all contributed equally towards the study; MKM, KR - Supervision of the study and data analysis, encouraged the investigators to plan and perform the study.

\section{Work attributed to:}

Institute of Nephro-Urology, Bangalore. India.

Orcid ID:

Dr. Shashikala N - (i) https://orcid.org/0000-0003-0178-9325

Dr. Mythri Shankar - io https://orcid.org/0000-0002-5382-8405

Dr. Kowsalya R - (D) https://orcid.org/0000-0003-4131-2337 